\section{PENGARUH STIMULASI SOMATOSENSORIK PADA KAKI TERHADAP PERUBAHAN KESEIMBANGAN DINAMIS LANSIA}

\section{Foot Somatosensory Stimulation on Dynamic Balance in Elderly}

\author{
Khabib Abdullah ${ }^{1}$, Yasin Galih Ardi ${ }^{2}$, Jihan Tsabita ${ }^{1}$
}

1. Prodi S1 Fisioterapi, Fakultas Ilmu Kesehatan, Universitas Muhammadiyah Surabaya

2. Klinik Fisoterapi Mulyosari Surabaya

\section{Riwayat artikel}

Diajukan: 3 Juni 2021

Diterima: 2 Juli 2021

\section{Penulis Korespondensi: \\ Khabib Abdullah \\ - Prodi S1 Fisioterapi, \\ Fakultas Ilmu \\ Kesehatan, Universitas \\ Muhammadiyah \\ Surabaya \\ e-mail: \\ abi337587@gmail.com}

\section{Kata Kunci:}

Somatosensorik, Keseimbangan, Lansia

\section{Abstrak}

Pendahuluan : Stimulasi somatosensorik pada kaki adalah salah satu metode untuk meningkatkan keseimbangan. Dari penelitian terdahulu, stimulasi tersebut mampu meningkatkan keseimbangan dinamis pada pasien diabetes melitus. Sampai saat ini belum diteliti pengaruh stimulasi somatosensorik pada kaki terhadap perubahan keseimbangan dinamis pada lansia. Tujuan: Untuk mengetahui pengaruh stimulasi somatosensorik pada kaki dalam meningkatkan keseimbangan dinamis pada lansia. Metode: Penelitian quasy eksperimental, sampel 20 lansia usia 60-68 (63,9 $\pm 2,1$ tahun), dibagi secara acak 2 kelompok (kelompok 1/perlakuan dan kelompok 2/kontrol). Stimulasi somatosensorik diberikan pada kaki lansia selama 30 menit, setiap hari selama 6 hari. Pengukuran keseimbangan dinamis (dengan timed up and go test/TUG dalam satuan detik), dilakukan pada pra dan paska perlakuan. Uji statistik menggunakan uji paired t test dan uji Wilcoxon. Hasil: Kelompok perlakuan, TUG berbeda bermakna $\mathrm{p}=0,02(12,9 \pm 0,9$ menjadi $11,1 \pm 1,3$ detik), sedangkan kelompok kontrol, TUG tidak berbeda bermakna $p=0,317(12,4 \pm 1,5$ menjadi $12,3 \pm 1,6$ detik). Kesimpulan: Stimulasi somatosensorik pada kaki meningkatkan keseimbangan dinamis pada lansia. Stimulasi ini akan meningkatkan input taktil telapak kaki dan proprioseptif sendi-sendi kaki yang berdampak pada kewaspadaan gerak yang meningkat saat berjalan. Beberapa gerakan pada stimulasi ini dapat dilakukan secara mandiri oleh lansia dan beberapa gerakan harus dikerjakan oleh fisioterapis, sehingga pelaksanaan diluar penelitian harus menyesuaikan.

\footnotetext{
Abstract

Background: Somatosensory stimulation of the feet is one method to improve balance. From previous studies, the stimulation is able to improve dynamic balance in patients with diabetes mellitus. Until now, the effect of somatosensory stimulation on the feet has not been studied on changes in dynamic balance in the elderly. Objective: To determine the effect of somatosensory stimulation on the feet in improving dynamic balance in the elderly. Method: Quasy experimental study, a sample of 20 elderly people aged 60-68 $(63.9+2.1$ years), randomly divided into 2 groups (group 1/treatment and group 2/control). Somatosensory stimulation was given to the feet of the elderly for 30 minutes, every day for 6 days. Measurement of dynamic balance (with timed up and go test/TUG in seconds), was carried out on pre and post treatment. Statistical test using paired t test and Wilcoxon test. Results: The treatment group, TUG was significantly different $p=0.02$ (12.9 \pm 0.9 to $11.1 \pm 1.3$ seconds), while the control group, TUG was not significantly different $p=0.317$ (12.4 \pm 1 , 5 becomes 12.3 \pm 1.6 seconds). Conclusion: Somatosensory stimulation of the feet improves dynamic balance in the elderly. This stimulation will increase the tactile input of the sole of the foot and proprioception of the foot joints which results in increased alertness of motion when walking. Some movements on this stimulation can be done independently by the elderly and some movements must be done by a physiotherapist, so that the implementation outside the research must adjust.
} 


\section{PENDAHULUAN}

Salah satu reseptor sensoris yang berperan pada keseimbangan adalah reseptor somatosensorik pada kaki (Kars et al., 2009). Reseptor somatosensorik terdiri dari reseptor cutaneous yang terdapat pada kulit, dan reseptor proprioseptor yang terdapat pada otot dan persendian (Vaillant et al., 2009). Saat berdiri dan berjalan, otak memerlukan input somatosensorik tersebut secara konsisten untuk memberikan informasi posisi kaki dan mempertahankan keseimbangan tubuh (Vaillant et al., 2009). Ketika terjadi penurunan fungsi reseptor somatosensorik pada kaki, misal pada pasien diabetes melitus dan pasien lansia, maka akan berisiko terjadi gangguan keseimbangan dan risiko jatuh (Chatchawan et al, 2015), (Vaillant et al., 2009). Pasien diabetes melitus akan mengalami penuruan rasa gerak pada kaki, sehingga meningkatkan goyangan/sway saat berjalan (Chatchawan et al, 2015). Jika dianalogikan, proses tersebut dapat dialami lansia karena secara fisiologis, lansia akan mengalami penurunan sensitivitas reseptor cutaneous dan proprioseptif pada kaki, sehingga lansia akan memiliki risiko jatuh yang lebih besar karena gangguan orientasi posisi kaki (Mesquita et al., 2015), (Goble et al.,2009). Kejadian jatuh pada lansia perlu dihindari, karena akan mengakibatkan trauma fisik dan psikis dan menurunkan fungsi kemandirian (Vaillant et al., 2009).

Salah satu teknik latihan untuk meningkatkan keseimbangan adalah stimulasi somatosensorik pada kaki (Chatchawan et al., 2015). Penelitian stimulasi somatosensorik oleh Chatchawan et al., (2015) dengan memberikan dosis 6 kali berturut-turut mampu meningkatan keseimbangan dinamis pada pasien diabetes melitus. Hal tersebut terjadi karena peningkatan sensasi rasa/taktil dan rasa gerak pada telapak kai, sehingga pasien diabetes lebih ringan dan stabil dalam berjalan. Namun hingga saat ini, belum ada penelitian serupa yang dilakukan pada lansia, Lansia mengalami permasalahan yang hampir sama dengan penderita DM yaitu penurunan sensasi taktil dan rasa gerak pada kaki, sehingga perlu dilakukan percobaan adopsi teknik stimulasi tersebut untuk lansia. Jika penelitian berhasil, maka akan memberikan alternatif lain teknik stimulasi untuk meningkatkan keseimbangan lansia di kemudian hari.

\section{METODE}

Jenis penelitian yang dilakukan adalah eksperimental lapangan dengan rancangan penelitian randomized control trial (single blinded). Penelitian ini mengambil sampel di UPTD Griya Wreda Rungkut Surabaya. Populasi pada penelitian ini adalah seluruh lansia di panti tersebut (75 lansia), dengan kriteria pengambilan sampel adalah : lansia 60-68 tahun, indeks massa tubuh antara 18,5 sampai $24,9 \mathrm{~kg} / \mathrm{m}^{2}$, tidak ada riwayat sakit stroke, parkinson dan patah tulang pada ekstremitas bawah, dapat berjalan mandiri tanpa menggunakan alat bantu seperti tripod, walker, tongkat dan kursi roda, mampu berkomunikasi dua arah. Dari 75 lansia, didapatkan 20 lansia sebagai sampel. Kemudian dilakukan randomisasi dengan undian, untuk menentukan 10 lansia masuk pada kelompok perlakukan, dan 10 lansia masuk dalam kelompok kontrol. Kelompok 1 adalah kelompok perlakuan dan kelompok 2 adalah kontrol.

Stimulasi somatosensorik diberikan pada sampel kelompok 1 yaitu pada kedua kaki lansia selama 30 menit setiap sesi, posisi lansia adalah duduk. Protokol stimulasi sesuai penelitian Chatchawan et al., (2015) yaitu stimulasi raba halus (dengan media minyak zaitun), raba kasar (dengan media handuk kering), stimulasi tekanan kulit, vibrasi kulit dan regangan kulit. Kemudian diberikan stimulasi gerakan pasif pada persendian ankle dan jari-jari kaki. Stimulasi dilakukan setiap hari selama 6 hari. Stimulasi diberikan oleh fisioterapis yang sudah lulus minimal D3 Fisioterapi. Sedangkan kelompok 2, kedua kaki diolesi dengan minyak zaitun, lalu dibiarkan selama 30 menit kemudian dikeringkan. Setelah penelitian selesai, kelompok 2 juga diberikan stimulasi yang sama dengan dosis 
yang sama dengan kelompok 1untuk etik penelitian.

Alat-alat dan bahan yang digunakan adalah minyak zaitun (hipo allergen), handuk kering (setiap sampel 1 handuk), meteran, stop watch, alat tulis.

Pengukuran keseimbangan dinamis dengan TUG (time up and go test dalam satuan detik). Pengukuran keseimbangan dinamis dilakukan pada pra dan paska perlakuan. Data lain yang diperoleh dari sampel adalah usia, dan nilai indeks masa tubuh. Data keseimbangan dinamis dikumpulkan dengan cara mengukur langsung pada sampel, kemudian dicatat pada formulir pengumpul data. Data yang sudah terkumpul dilakukan input pada program SPSS 17.0 kemudian dilakukan analisis deskriptif, uji normalitas, uji beda dengan paired $t$ tes dan Wilcoxon dengan tingkat kemaknaan $\mathrm{p}<0,05$. Penelitian ini mendapatkan kelayakan etik dari komisi etik Fakultas Kedokteran Universitas Airlangga nomor 58/EC/KEPK/FKUA/2016.

\section{HASIL PENELITIAN}

Rerata dan simpangan baku umur dan IMT kelompok 1/perlakuan $(63,8 \pm 1,8$ tahun) dan $\left(22,1 \pm 1,5 \mathrm{~kg} / \mathrm{m}^{2}\right)$. Sedangkan kelompok 2/kontrol $(64,1 \pm 2,5$ tahun) dan $\left(22,4 \pm 1,6 \mathrm{~kg} / \mathrm{m}^{2}\right)$. Data umur dan IMT antar kelompok adalah homogen karena nilai p>0,05 pada uji homogenitas (pada tabel 1).

Tabel 1 Rerata dan simpangan baku umur dan IMT sampel kedua kelompok

\begin{tabular}{|c|c|c|c|}
\hline \multirow[t]{2}{*}{ Karakteristik } & \multicolumn{2}{|c|}{$\begin{array}{l}\text { Rerata } \pm \text { SD } \\
\text { kelompok }\end{array}$} & \multirow[t]{2}{*}{$\mathrm{p}^{*}$} \\
\hline & 1 & 2 & \\
\hline $\begin{array}{c}\text { Indeks masa } \\
\text { tubuh } \\
\left(\mathrm{kg} / \mathrm{m}^{2}\right)\end{array}$ & $22,1 \pm 1,5$ & $22,4 \pm 1,6$ & 0.77 \\
\hline Usia (tahun) & $63,8 \pm 1,8$ & $64,1 \pm 2,5$ & 0.55 \\
\hline Jumlah & 10 & 10 & \\
\hline
\end{tabular}

Rerata dan simpangan baku nilai TUG pra perlakuan pada kelompok 1 adalah $12,9 \pm 0,9$, sedangkan paska perlakuan menjadi $11,1 \pm 1,3$. Keduanya memiliki data dengan distribusi tidak normal, sehingga uji beda menggunakan uji Wilcoxon. Sedangkan untuk rerata dan simpangan baku nilai TUG pra perlakuan pada kelompok 2 adalah 12,4 $\pm 1,5$ kemudian pada paska perlakuan menjadi 12,3 $\pm 1,6$. Keduanya memiliki distribusi data yang normal, sehingga uji beda menggunakan uji Ipaired $t$ test(pada tabel 2).

Tabel 2. Nilai rerata dan simpangan baku uji normalitas variabel penelitian

\begin{tabular}{ccc}
\hline \multirow{2}{*}{ Karakteristik } & \multicolumn{2}{c}{$\begin{array}{c}\text { Rerata } \pm \text { SD } \\
\text { kelompok }\end{array}$} \\
\cline { 2 - 3 } TUG (detik) & 1 \\
Pra \\
perlakuan \\
$\begin{array}{c}\text { Paska } \\
\text { perlakuan }\end{array}$ & $12,9 \pm 0,9 *$ & $12,4 \pm 1,5$ \\
\hline
\end{tabular}

*Distribusi data tidak normal

Untuk menentukan perbedaan signifikansi pada kelompok 1 menggunakan uji Wilcoxon dan didapatkan hasil berbeda bermakna pada tabel 3 .

Tabel 3. Uji wilcoxon keseimbangan dinamis kelompok 1

\begin{tabular}{ccc}
\hline Variabel & Rerata \pm Sd & $\mathrm{p}$ \\
\hline TUG pra & $12,9 \pm 0,9$ & \\
& & $0.002 *$ \\
paska & $11,1 \pm 1,3$ & \\
Keterangan : $*$ signifikan jika $\mathrm{p}<0,05$ &
\end{tabular}

Sedangkan untuk mengetahui signifikansi perbedaan keseimbangan dinamis pada kelompok 2, dilakukan uji paired t test, dan didapatkan hasil tidak berbeda bermakna. (tabel 4) 
Tabel 4. Uji paired t test keseimbangan dinamis kelompok 2

\begin{tabular}{ccc}
\hline Variabel & Rerata \pm Sd & $\mathrm{p}$ \\
\hline TUG pra & $12,4 \pm 1,5$ & \\
paska & $12,3 \pm 1,6$ & 0.343 \\
\hline
\end{tabular}

Keterangan : * signifikan jika $\mathrm{p}<0,05$

Jika digambarkan dalam grafik batang, maka kelompok 1 terlihat terjadi peningkatan keseimbangan dinamis dengan menurunnya waktu tempuh tes, sedangkan kelompok 2 tidak terjadi (grafik 1).

Grafik 1. Perbedaan keseimbangan dinamis pra dan paska perlakuan pada kedua kelompok

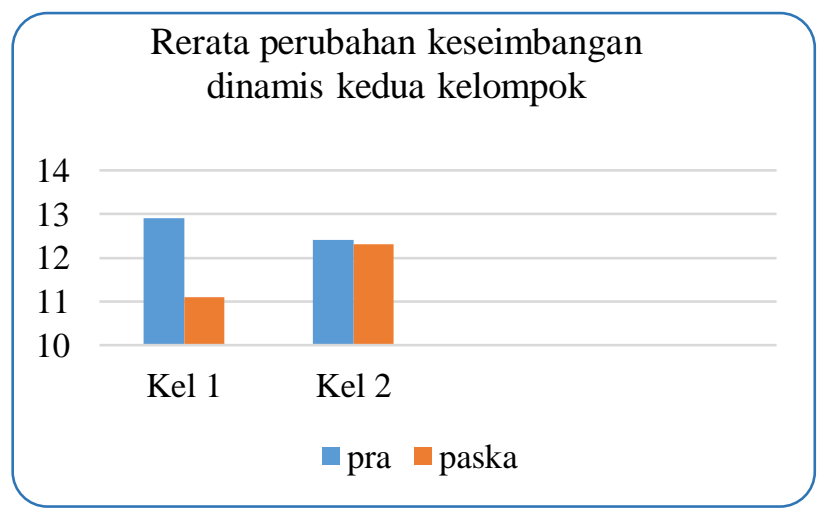

\section{PEMBAHASAN}

\section{Data karakteristik sampel}

Menurut Sihvonen (2004), bahwa pada usia 60-70 tahun akan mengalami penurunan kestabilan tubuh saat berdiri, karena peningkatan body sway, sehingga pada penelitian ini memilih sampel pada rentang usia tersebut. Sampel pada penelitian ini juga dipilih dengan kategori berat badan yang normal weight, karena menurut Sihvonen (2004) dan Greve et al. (2007), pada seseorang yang obesitas akan mengalami instabilitas postur karena tidak memiliki reaksi yang cepat tubuh ketika terjadi gangguan keseimbangan. Dari tabel 1 dapat disimpulkan bahwa kedua kelompok memiliki homogenitas dari variabel usia dan indeks masa tubuh, sehingga lebih valid untuk dibandingkan.

\section{Perbedaan keseimbangan pra dan paska stimulasi}

Sesuai dengan tabel 3 dan 4, maka kelompok 1/perlakuan memiliki perbedaan bermakna pada variabel keseimbangan dinamis dibandingkan dengan kelompok 2 . Nilai $\mathrm{p}$ kelompok $1=0.002$ dan nilai $\mathrm{p}$ kelompok $2=0.343$. Kemudian pada grafik 1, dapat dilihat bahwa pada kelompok 1 terjadi penurunan waktu tempuh saat berjalan $(12,9 \pm 0,9$ menjadi $11,1 \pm 1,3$ detik), sehingga dapat dikatakan bahwa keseimbangan dinamis kelompok 1 meningkat dibandingkan kelompok 2/kontrol $\quad(12,4 \pm 1,5$ menjadi $12,3 \pm 1,6$ detik).

Pemberian stimulasi somatosensorik pada kaki yang berulang (setiap hari selama 6 hari) pada kelompok 1, akan semakin meningkatkan sensitivitas reseptor somatosensorik, meningkatkan stimulasi neuromuskuler ke sistem saraf pusat dan meningkatan elastisitas otot area kaki. Peningkatan keseimbangan pada kelompok 1 juga dimungkinkan terjadi karena stimulasi proprioseptif pada kaki direspon secara kontinyu oleh cerebellum (Gjelsvik, 2008). Secara fisiologis, cerebellum bertugas sebagai error correction pada setiap gerakan tubuh yang berulang-ulang, sehingga muncul output gerakan yang lebih halus dan menjadi skill (Gjelsvik, 2008). Sedangkan menurut Goble et al., (2009) bahwa input somatosensorik dari kaki digunakan tubuh untuk memonitor posisi dan kecepatan gerak sehingga berperan dalam keseimbangan dinamis saat berjalan. Sehingga ketika input tersebut dikuatkan dengan stimulasi, maka monitoring posisi kaki dan kecepatan bergerak menjadi optimal.

Menurut Kafa (2015) bahwa rangsangan tekanan pada telapak kaki seperti pada gerakan stimulasi penelitian ini akan direspon oleh reseptor merkel's dan rangsangan regangan pada kulit kaki akan direspon oleh reseptor ruffini's, aktivasi kedua reseptor ini sangat berpengaruh dalam mempertahankan keseimbangan. Aplikasi vibrasi manual pada kaki sampel juga 
berpengaruh terhadap sensitivitas raba kulit, hal tersebut sesuai dengan penelitian oleh Dhruv et al.,(2002) yang menyatakan bahwa pemberian stimulasi somatosensorik dengan vibrasi pada telapak kaki lansia sehat selama beberapa menit, mampu memberikan efek segera terhadap peningkatan sensitivitas raba pada telapak kaki.

Gerakan pasif pada sendi ankle berulang-ulang juga akan merangsang reseptor otot muscle spindle. Menurut Kafa (2015), bahwa muscle spindle sebagai komponen utama pembangun proprioseptif pada sendi ankle yang akan memberikan input menuju cerebellum sebagai pusat pengkoreksi reaksi gerakan yang mengganggu keseimbangan.

Nilai keseimbangan dinamis yang meningkat pada kelompok 1 sesuai dengan penelitian oleh Chatchawan et al., (2015) yang memberikan intervensi masase dan gerakan pasif pada kaki dengan dosis 30 menit setiap sesi, 3 kali per minggu selama 2 minggu dan didapatkan hasil peningkatan keseimbangan dinamis pada pasien diabetes mellitus.

Untuk penelitian lebih lanjut, dapat dilakukan dengan melihat efek mempertahankan keseimbangan dinamis pada sampel lansia paska stimulasi.

\section{KESIMPULAN}

Stimulasi somatosensorik pada kaki lansia, dengan dosis setiap hari selama 6 hari, dapat meningkatkan keseimbangan dinamis dibandingkan dengan kontrol. Gerakan - gerakan pada stimulasi ini dapat dicontoh untuk dilakukan, beberapa dapat dikerjakan mandiri dan beberapa harus dilakukan oleh fisioterapis/nakes lain yang berkompeten. Untuk penelitian lebih lanjut, dapat diteliti tentang berapa lama mempertahankan efek keseimbangan dinamis yang telah didapatkan sehingga dapat memformulakan dosis yang sesuai.

\section{DAFTAR PUSTAKA}

Chatchawan, Uraiwan; Eungpinichpong, Wichai; Plandee, Piyawan; Yamauchi, Junichiro (2015), Effect of Thai Foot
Massage on balance performance, Medical Science Monitor Basic Research, $21:$ 68-75.

Dhruv, Neel T; Niemi, James B; Harry, Jason D; Lipsitz, Lewis A; Collins, James J, (2002), Enhancing tactile sensation in older adults with electrical noise stimulation, NEURO REPORT, Vol 13 No 516 April 2002.

Gjelsvik, Bente (2008), The Bobath concept for adult neurology, Georg Thieme Verlag, Sturtgart Germany.

Goble, Daniel J; Coxon, James P; Nicole, Annouchka; Swinnen, Stephan P (2009), Proprioceptive sensibility in the elderly: Degeneration, functional consequences and plastic-adaptive processes, Neuroscience and Biobehavioral Reviews 33 (2009) 271278

Greve, Julia; Alonso, Angelica; Bordini, Ana Carolina P.G; Camanho, Gilberto Luis (2007), Correlation between body mass index and Postural balance, Clinics. 2007;62(6):717-20.

Kafa, Nihan (2015), Foot Sensation, Balance and Proprioception, OMICS Group eBooks 731 Gull Ave, Foster City, CA 94404, USA.

Kars, Cojanne; Hijmans, Juha; Geertzen, Jan; Zijlstra, Wiebren (2009), The effect of reduced somatosensation on standing balance : A systematic review, Journal Of Diabetes Science and Technology Vol. 3 July 2009.

Mesquita, Laiana; Carvalho, Fabiana; Freire, Lara; Neto, Osmar; Zangaro; Renato (2015), Effect of two exercise protocols on postural balance of eldery women : a randomized controlled trial, Biomed Central Geriatrics Journal. 
Sihvonen, Sanna (2004), Postural balance and aging : Cross sectional comparative studies and balance training intervention, University of Jyvaskila, Finlandia.

Vaillant, Jacques; Rouland, Audrey; Martigne, Pascale; Braujou, Renaud; Nissen, Michael; Miousse, Jean; Vuillerme, Nicolas; Nougier, Vincent; Juvin, Robert (2009), Massage and mobilization of the feet and ankles in eldery adults : Effect on clinical balance performance, Manual Therapy Journal Elsevier. 